\title{
THE RELATIONSHIP BETWEEN GENDER TRAITS AND AMBIVALENT SEXISM
}

\author{
S. Agut, F. Lozano-Nomdedeu, R. Peris \\ Universitat Jaume I (SPAIN)
}

\begin{abstract}
Gender is still a relevant variable in many settings if our interest lies in examining the overwhelming unbalanced percentage of women and men occupying positions of high status and power. One of the factors contributing to this gender inequality_-to the advantage of men and disadvantage of women-is the existence of what is called ambivalent sexism. This construct includes both hostile and benevolent sexism, which are positively related to each other, thus indicating the ambivalent attitudes that people may have toward women. Hostile sexism is an adversarial view of gender relations and as such explicitly expresses antipathy. It reflects attitudes of male superiority and dominance over women. By contrast, on the surface benevolent sexism seems to convey a positive attitude toward women, but in fact it implies positive attitudes towards traditional women by idealizing women who enact traditional roles. The internalization of these hostile and benevolent attitudes could be a consequence of gender identity (femininity/expressive and masculinity/instrumental). In this context, the aim of this study is twofold: first, to explore how undergraduate students perceive themselves in terms of gender traits (i.e., instrumental and expressive attributes), and second, to examine the relationship between self-ratings of gender traits and ambivalently sexist attitudes toward women. The participants were 120 undergraduate students ( $n=32$ men and $n=88$ women). They rated themselves on instrumental and expressive traits based on the Bem Sex Role Inventory (Bem, 1974) and also on ambivalently sexist attitudes, drawing from the Ambivalent Sexism Inventory (Glick \& Fiske, 1996). As expected, the results showed that women self-described in a more expressive way, while men's self-ratings were more instrumental. In addition, participants presented a low degree of sexist attitudes and both sub-scales correlated positively. Some expressive attributes such as warmth or childlike correlated positively with benevolent sexism, while only one instrumental trait (egoism) positively correlated with hostile sexism. These findings reveal the role of gender traits in the configuration of attitudes toward women. The implications of the results for education and the university teaching-learning process are discussed and some future research lines are also suggested.
\end{abstract}

Keywords: gender traits, hostile sexism, benevolent sexism, undergraduate students.

\section{INTRODUCTION}

Inequality between men and women in the world of work continues to be widespread and begins with women's limited access to the job market and, once in it, their restricted access to quality employment opportunities [1]. Gender is therefore still a relevant variable in organizational settings if our interest lies in examining the overwhelming unbalanced percentage of women and men occupying leadership roles. In no country do women have equality with men as executives in the public sector, corporative board members, corporate officers, or CEOs [2]. For instance, European Union (EU-28) figures for 2016 show that women accounted for only $5 \%$ of CEOs, and in the United States the percentage is just as low at $5.2 \%$ [3]. One of the factors that contribute to this gender inequality-to the advantage of men-is the existence of what is called ambivalent sexism.

According to ambivalent sexism theory $[4,5,6]$, sexism is a multidimensional construct encompassing two sets of sexist attitudes: hostile and benevolent. Hostile attitudes imply a clear antipathy toward women and justify men's dominant social status through the derogatory and hostile treatment of women. In turn, benevolent sexism justifies men's dominance through subjectively positive attitudes toward women. It encompasses protective paternalism (chivalry toward women), complementary gender differentiation (stereotypical roles for women), and heterosexual intimacy (the belief that men and women are incomplete without each other). While this attitude seems to be positive, this benevolent component is in fact negative, because it reinforces traditional stereotyping and masculine dominance (e.g., the man as the provider and woman as his dependent), with frequently damaging consequences. Rather than denigrating women who adopt nontraditional roles, benevolent sexists idealize women who perform traditional roles [7]. 
The internalization of these hostile and benevolent attitudes could partially stem from the internalization of traditional gender roles, that is, the shared beliefs that members of a society hold about the traits of women and men. Gender roles encourage most adults to conform to these shared beliefs by confirming others' expectations and by internalizing them as personal standards for their own behavior [8]. Gender roles govern a number of contexts including occupations, family relationships, and social relationships.

One influential long-standing stream in the research on gender identity based on gender-stereotypical personality traits is represented by Sandra Bem. She developed a conception of the sex-typed person as someone who has internalized society's sex-typed standards of desirable behavior for men and women. These personality characteristics were selected as masculine or feminine on the basis of sextyped social desirability. The Bem Sex-Role Inventory (BSRI) contains a number of desirable personality traits that are stereotypical either of men (e.g., self-reliant, assertive, forceful) or of women (e.g., affectionate, sympathetic, warm) [9]. By representing gender identity in this way, people who endorse gender stereotypical traits through self-description are assumed to incorporate them into their self-concepts and to guide their behavior in terms of this self-knowledge [10].

Previous empirical evidence has explored the relationship between gender identity and sexism, finding a link between masculinity, and heroism and chivalry (a form of benevolent sexism). It is argued that masculinity pressurizes men to take heroic risks, as a means of displaying manhood that may increase social status and power. Men may be more likely to exhibit these heroically risky behaviors toward traditional women because they are expected to be chivalrous, and help "damsels in distress" [11]. Masculine identification also predicted favorable attitudes toward masculine men and traditional women, and negative attitudes toward feminine men [12]. In this context, the present study explores, first, how undergraduate students perceive themselves in terms of gender traits, and second, the relationship between self-ratings of gender traits and ambivalently sexist attitudes toward women.

\section{METHODOLOGY}

\subsection{Sample and procedure}

The sample was composed of 200 undergraduate students ( 32 men, and 88 women) attending a public university in the east of Spain, aged between 20 and 33 years $(M=21.80, S D=1.95)$. The students participated in the study during a class exercise. No incentives were involved, and confidentiality of their responses was fully guaranteed.

\subsection{Variables and measures}

The variables analyzed in the study were:

- Gender. Male - female.

- Age. Years old.

- Gender characteristic attributes. The participants were asked to attribute themselves traits, that is, how well they fit into the traditional sex role, on a 5-point scale ranging from 1 (No characteristic) to 5 (Totally characteristic). The attributes were 18 items from the short version of the Bem Sex Roles Inventory (BSRI) [9] that had previously been demonstrated as stereotypically masculine and stereotypically feminine in the cultural context of Spain [13]. Nine of the items evaluate stereotypically masculine attributes (e.g., aggressive) $(\alpha=0.75)$ and the other nine, stereotypically feminine attributes (e.g., warm) $(\alpha=0.76)$.

- Ambivalent sexism. Participants completed the 22-item Ambivalent Sexism Inventory (ASI) [11], which measures both hostile and benevolent sexism toward women. They were asked to indicate agreement or disagreement on a scale ranging from 0 (Strongly disagree) to 5 (Strongly agree) with no midpoint (respondents were obliged to agree or disagree at least slightly with each item). Eleven of the items evaluate hostile sexism (e.g., "Women seek power by gaining control over men") ( $\alpha=0.89)$ and the other eleven, benevolent sexism (e.g., "A good woman should be set on a pedestal") $(\alpha=0.86)$. 


\subsection{Data analyses}

Data analysis was performed using the SPSS statistics program. Descriptive analysis and internal consistencies (Cronbach's $\alpha$ ) were performed. We carried out $t$ tests to explore the possible differences between male and female participants in how undergraduate students perceive themselves in terms of gender traits and also ambivalent sexism. We used Pearson correlations to examine the relationship between self-ratings of gender traits and ambivalently sexist attitudes toward women.

\section{RESULTS}

Below we present the main results for the self-attributed gender traits, self-ratings of ambivalent sexism and the relationship between them.

\subsection{Self-attributed gender traits}

As expected, women self-described in a more feminine/expressive way $\left(M_{\text {female }}=4.78, M_{\text {male }}=4.30, p\right.$ $=.003)$, while men's self-ratings were more masculine/instrumental $\left(M_{\text {male }}=4.02, M_{\text {male }}=3.38, p<\right.$ .001). Differences among them appeared in some traits. In particular, as shown in Table 1, men perceived themselves as more masculine in the attributes of athletic, willing to take risks, aggressive, individualistic, and egoistic. By contrast, women assessed themselves in a more feminine way in the traits of sensitive to the needs of others, understanding, and cry easily.

Table 1. Means and standard deviations of self-attributed gender traits of men and women

\begin{tabular}{|c|c|c|c|c|c|}
\hline \multirow[b]{2}{*}{ Masculine items } & \multicolumn{2}{|c|}{ Men } & \multicolumn{2}{|c|}{ Women } & \multirow[b]{2}{*}{$\mathrm{p}$} \\
\hline & Mean & SD & Mean & SD & \\
\hline Athletic & 5.31 & 1.28 & 3.50 & 1.42 & $<.001$ \\
\hline Strong personality & 4.53 & 1.46 & 4.74 & 1.29 & n.s. \\
\hline Willing to take risks & 3.97 & 1.42 & 3.27 & 1.40 & $<.025$ \\
\hline Dominant & 3.75 & 1.54 & 3.48 & 1.30 & n.s. \\
\hline Aggressive & 3.06 & 1.27 & 2.43 & 1.17 & $<.025$ \\
\hline Act as a leader & 4.22 & 1.45 & 3.66 & 1.46 & n.s. \\
\hline Individualistic & 4.19 & 1.40 & 3.35 & 1.40 & $<.01$ \\
\hline Hard-hearted & 3.97 & 1.28 & 3.69 & 1.22 & n.s. \\
\hline Egoistic & 3.16 & 1.46 & 2.33 & .84 & $<.01$ \\
\hline Feminine items & Mean & SD & Mean & SD & $\mathrm{p}$ \\
\hline Affectionate & 4.75 & 1.16 & 5.08 & 1.37 & n.s. \\
\hline Sensitive to the needs of others & 4.69 & 1.15 & 5.41 & 1.12 & $<.025$ \\
\hline Understanding & 5.16 & 1.17 & 5.88 & 0.93 & $<.01$ \\
\hline Compassionate & 4.75 & 1.14 & 5.11 & 1.21 & n.s. \\
\hline Warm-hearted & 5.03 & 1.40 & 5.09 & 1.31 & n.s. \\
\hline Tender & 4.38 & 1.21 & 4.86 & 1.28 & n.s. \\
\hline Love children & 4.56 & 1.62 & 4.98 & 1.70 & n.s. \\
\hline Cry easily & 2.63 & 1.26 & 4.10 & 1.66 & $<.001$ \\
\hline Submissive & 2.81 & 1.18 & 2.56 & 1.29 & n.s. \\
\hline
\end{tabular}




\subsection{Ambivalent sexism}

Our results showed that in general terms the participants displayed low scores of ambivalent sexism $(M=1.96, S D=0.80)$. When we compare the men's and women's scores in the two subscales (hostile and benevolent sexism), male scores were higher in hostile sexist attitudes. By contrast, we found no significant differences with regard to benevolent sexism (see Table 2).

Table 2. Means and standard deviations of women's and women's ambivalent sexism

\begin{tabular}{|c|c|c|c|c|c|}
\hline \multirow[b]{2}{*}{ Sexism subscales } & \multicolumn{2}{|c|}{ Men } & \multicolumn{2}{|c|}{ Women } & \multirow[b]{2}{*}{$\mathrm{p}$} \\
\hline & Mean & SD & Mean & SD & \\
\hline Hostile & 2.25 & 0.78 & 1.71 & 0.89 & $<.01$ \\
\hline Benevolent & 2.13 & 0.88 & 2.05 & 0.92 & n.s. \\
\hline
\end{tabular}

\subsection{Relationship between self-attributed gender traits and ambivalent sexism}

The analysis of the relationships between the study variables in the complete sample, reported in Table 3, revealed no relation between masculine and feminine traits. Both sub-scales of ambivalent sexism correlated positively with each other. Moreover, while masculine traits were not associated to either hostile or benevolent sexism, feminine traits were positively related to benevolent sexism. In particular, some feminine attributes (i.e., affectionate, compassionate, warm-hearted, tender, and childlike) correlated positively with benevolent sexism, while only one instrumental trait (i.e., egoistic) correlated with hostile sexism in a positive way.

Table 3. Pearson correlations among the study variables

\begin{tabular}{l|c|c|c|c|}
\hline \hline & $\begin{array}{c}\text { Masculine } \\
\text { traits }\end{array}$ & $\begin{array}{c}\text { Feminine } \\
\text { traits }\end{array}$ & $\begin{array}{c}\text { Hostile } \\
\text { sexism }\end{array}$ & $\begin{array}{c}\text { Benevolent } \\
\text { sexism }\end{array}$ \\
\hline Masculine traits & - & - & - & - \\
\hline Feminine traits & -0.171 & - & - & - \\
\hline Hostile sexism & 0.096 & 0.086 & - & - \\
\hline Benevolent sexism & 0.029 & $0.348^{* * *}$ & $0.572^{* * *}$ & - \\
\hline \hline
\end{tabular}

${ }^{* * *} p<0.001$. The other coefficients are non-significant

\section{CONCLUSIONS}

The aim of this study was twofold: to explore how undergraduate students assess themselves in terms of gender traits (i.e., instrumental/masculine and expressive/feminine attributes) and to examine the relationship between self-ratings of gender traits and ambivalently sexist attitudes toward women. As expected, the findings show that women self-described in a more expressive way, while men's selfratings were more instrumental. These results confirm that, in general, the participants have fully internalized society's sex-typed standards of desirable traits for men and women, as a gender schema. This gender schema is then used to organize subsequent experiences [9, 10], and guide their cognition and behavior, such as attitudes toward other groups (e.g., women). In particular, we explored sexist attitudes toward women, known as ambivalent sexism. Our results evidence that both male and female undergraduate students presented a low degree of both types of sexism, but we found some differences among them. Male scores were higher than female scores in hostile sexist attitudes, namely, dominative paternalism, derogatory beliefs, and heterosexual hostility. By contrast, we found no significant differences among participants regarding benevolent sexism. This implies subjectively positive (for the sexist) attitudes toward women in traditional roles, such as protective paternalism, idealization of women, and desire for intimate relations. The fact that the scores were low is good news. However, in an ideal world, men would not present higher hostile sexism scores than women.

In addition, one very typical masculine trait (egoistic) positively correlated to hostile sexist attitudes, as did some feminine traits to benevolent sexism, particularly the attributes of affectionate, 
compassionate, warm-hearted, tender, and childlike. This suggests that when a man assumes it is natural to be egoistic, and a woman also accepts some stereotypical female traits as appropriate (i.e., affectionate, compassionate, warm-hearted, tender, and childlike), both individuals are leaving the door open to consent and acceptance of certain sexist attitudes toward women as appropriate and respectful, although this is clearly not the case. The problem of holding hostile and benevolent sexist attitudes is that they justify and maintain the patriarchal system and traditional gender roles $[4,5,6]$. A more serious consequence may be that they derive in acts of gender violence against women.

Society, families, and the education system have a key responsibility to firmly and proactively promote education based on values of respect, tolerance, and positive attitudes toward gender equality. Gender equality is a global priority for UNESCO and inextricably linked to its efforts to ensure the right to education and support for meeting its sustainable development goals (SDGs). In fact, the Education 2030 agenda recognizes that gender equality requires an approach that ensures that girls and boys, women and men not only gain access to and complete education cycles, but are empowered equally in and through education [14].

Through appropriate socialization models, children should internalize the attitude that women and men have the same rights and obligations as citizens, and that biological differences between the sexes neither explain nor justify the unequal, degrading, and discriminatory treatment that women continue to suffer across the world, even in the more developed countries. Future research should explore ways of integrating effective concrete actions to promote values and attitudes of gender equality into educational systems, and also analyze the extent to which traditional gender roles and stereotypes are disappearing as a consequence of educational systems based on gender equality; studies should also examine and monitor how far the promotion of more equalitarian attitudes leads to a decrease in violent attitudes toward women.

\section{REFERENCES}

[1] International Labour Organization, "World employment social outlook. Trends for women 2017. International Labour Office, Geneva, 2017. Retrieved from http://www.ilo.org/wcmsp5/groups/ public/---dgreports/---inst/documents/publication/wcms_557245.pdf

[2] L.L. Carli \& A.H. Eagly. "Women face a labyrinth: an examination of metaphors for women leaders", Gender in Management: An International Journal, vol. 31, no: 8, pp.514-527, 2016

[3] Catalyst, "Women in management", 2017. Retrieved from http://www.catalyst.org/knowledge/women-management

[4] P. Glick \& S. Fiske, "The ambivalent sexism inventory: differentiating hostile and benevolent sexism", Journal of Personality and Social Psychology, vol. 12, pp. 1323-1334, 1996.

[5] P. Glick \& S. Fiske, "Hostile and benevolent sexism: Measuring ambivalent sexist attitudes toward women", Psychology of Women Quarterly, vol. 21, pp. 119-135, 1997.

[6] P. Glick \& S. Fiske, "An ambivalent alliance: hostile and benevolent sexism as complementary justifications of gender inequality”, American Psychologist, vol. 56, pp.109-118, 2001.

[7] P. Glick \& S. Fiske, "Ambivalent Sexism Revisited", Psychology of Women Quarterly, vol. 35, pp. 530- , 2011.

[8] W. Wood \& A. H. Eagly, "Biosocial Construction of Sex Differences and Similarities in Behavior", in Advances in Experimental Social Psychology (J.M. Olson and M.P. Zanna eds.), pp. 55- pp.123, Burlington, Academic Press, 2012.

[9] S. Bem, "The measurement of psychological androgyny", Journal of Consulting and Clinical Psychology, no. 42, pp. 155-62, 1974.

[10] W. Wood \& A.H. Eagly, "Two traditions of research on gender identity", Sex Roles, vol. 73, pp. 461-473, 2015.

[11] Becker, S. W. \& A.H. Eagly, "The heroism of women and men", American Psychologist, 59(3), 163-178, 2004. 
[12] M.L. Wilkerson, "How Sexism makes the man: Examining the relationship between masculinity, ambivalent sexism, and gender stereotypes", Lawrence University Honors Projects. Paper 55, 2014. Retrieved from

https://lux.lawrence.edu/cgi/viewcontent.cgi?referer=https://www.google.es/\&httpsredir=1\&articl $e=1063 \&$ context=luhp

[13] I. Cuadrado, "Valores y rasgos estereotípicos de género de mujeres líderes", Psicothema Vol. 16, pp. 279-284, 2004.

[14] UNESCO, "Education and gender equality", 2018. Retrieved from https://en.unesco.org/themes/education-and-gender-equality 